\title{
Design and evaluation of an optimized W/Cu interlayer for W monoblock components
}

\author{
Aurelia Herrmann, H. Greuner ${ }^{*}$, M. Balden and H. Bolt \\ Max-Planck-Institut für Plasmaphysik, EURATOM Association, 85748 Garching, Germany
}

\begin{abstract}
Divertor plasma-facing components of future fusion reactors should be able to withstand heat fluxes of $10-20 \mathrm{MW} / \mathrm{m}^{2}$ in stationary operation. Tungsten blocks with an inner cooling tube made of CuCr1Zr, so-called monoblocks, are potential candidates for such water-cooled components. To increase the strength and reliability of the interface between the $\mathrm{W}$ and the cooling tube of a Cu-based alloy (CuCr1Zr), a novel advanced $\mathrm{W}$-fibre/Cu metal matrix composite (MMC) was developed for operation temperatures up to $550^{\circ} \mathrm{C}$. Based on optimization results to enhance the adhesion between fibre and matrix, $\mathrm{W}$ fibres $\left(\mathrm{W}_{\mathrm{f}}\right)$ were chemically etched, coated by physical vapour deposition with a continuously graded $\mathrm{W} / \mathrm{CuPVD}$ interlayer and then heated to $800^{\circ} \mathrm{C}$. The $\mathrm{W}_{\mathrm{f}} / \mathrm{Cu} \mathrm{MMC}$ was implemented by hot-isostatic pressing and brazing process in monoblock mock-ups reinforcing the interface between the plasma-facing material and the cooling channel. The suitability of the MMC as an efficient heat sink interface for water-cooled divertor components was tested in the high heat flux (HHF) facility GLADIS. Predictions from finite element simulations of the thermal behaviour of the component under loading conditions were confirmed by the HHF tests. The $\mathrm{W}_{\mathrm{f}} / \mathrm{Cu} \mathrm{MMC}$ interlayer of the mock-ups survived cyclic heat loads above $10 \mathrm{MW} / \mathrm{m}^{2}$ without any damage. One W block of each tested mock-up showed stable thermal behaviour at heat fluxes of up to $10.5 \mathrm{MW} / \mathrm{m}^{2}$.
\end{abstract}

Keywords: Metal matrix composite, monoblock , divertor, heat flux tests, W fibre, graded W/Cu interlayer

\section{Introduction}

For DEMO heat fluxes between $10-20 \mathrm{MW} / \mathrm{m}^{2}$ in the divertor region are expected [1]. According to the reference design of the Model A of the European Power Plant Conceptual Study (PPCS) [2, 3], the load has to be removed efficiently from the tungsten (W) plasma-facing material (PFM) to the water-cooled heat sink material, the copper alloy (CuCr1Zr) tubes. Due to the mismatch in the coefficients of thermal expansion (CTE) between W (4.2 x 10-6 $\left.\mathrm{K}^{-1}\right)$ and CuCr1Zr (17.6 x $10^{-6} \mathrm{~K}^{-1}$ ) heat sink, a soft intermediate Oxygen Free High Conductivity (OFHC) Cu layer is included [4]. This low temperature divertor concept (monoblock design) tolerates heat flux of $15 \mathrm{MW} / \mathrm{m}^{2}$ with a coolant temperature of $150^{\circ} \mathrm{C}$.

For efficient energy production, high temperature He cooling concepts are preferred. For the alternative water-cooling concept the increase of the cooling water temperature to at least $300^{\circ} \mathrm{C}$ is desired. This would lead to temperatures of up to $550^{\circ} \mathrm{C}$ at the interface between the PFM (W) and heat sink material (CuCr1Zr) [5]. However, the mechanical properties of the current $\mathrm{Cu}$-based material at this high temperature are insufficient [6]. Due to the temperature gradient and different CTE between $\mathrm{W}$ and Cu-based materials, high stresses occur at the interface of PFM and the heat sink material. Furthermore, Cu-based materials like $\mathrm{CuCr} 1 \mathrm{Zr}$ or OFHC $\mathrm{Cu}$ are prone to embrittlement under neutron irradiation below $200^{\circ} \mathrm{C}$ and to irradiation-induced creep above $350^{\circ} \mathrm{C}$ [4].
One solution proposed is a novel optimized watercooled monoblock divertor component consisting of $\mathrm{W}$ as PFM and $\mathrm{W}_{\mathrm{f}} / \mathrm{Cu}$ metal matrix composites (MMC) as reinforcement of the critical zone between PFM and the CuCr1Zr cooling tube. A W fibre-reinforced $\mathrm{Cu}$ MMC has the potential to strengthen the interface of PFM and the heat sink material. It may also provide a high creep resistant alternative to conventional $\mathrm{Cu}$ based materials for operation at high temperatures [7, 8]. MMCs also offer a wide range of material properties for tailoring the interface. The attraction of $\mathrm{W}_{\mathrm{f}} / \mathrm{Cu} \mathrm{MMC}$ for its use as heat sink material in fusion application is twofold: (1) The W fibres provide the necessary strength of the composite at high temperatures, while (2) the $\mathrm{Cu}$ matrix provides the required high thermal conductivity for efficient heat removal in the cooling system.

\section{Material and experimental evaluation}

\subsection{Optimized monoblock mock-up}

The geometry of the monoblock mock-ups was chosen in a way such that the results of the HHF tests can be compared to those of the ITER divertor mockups. Figure 1 shows a manufactured mock-up consisting of four individual $\mathrm{W}$ monoblocks (\#1...\#4). The reference design was slightly modified such that the $\mathrm{W}_{\mathrm{f}} / \mathrm{Cu} \mathrm{MMC}$ reinforces the cooling tube. Based on published simulation results [9], the orientation of the 


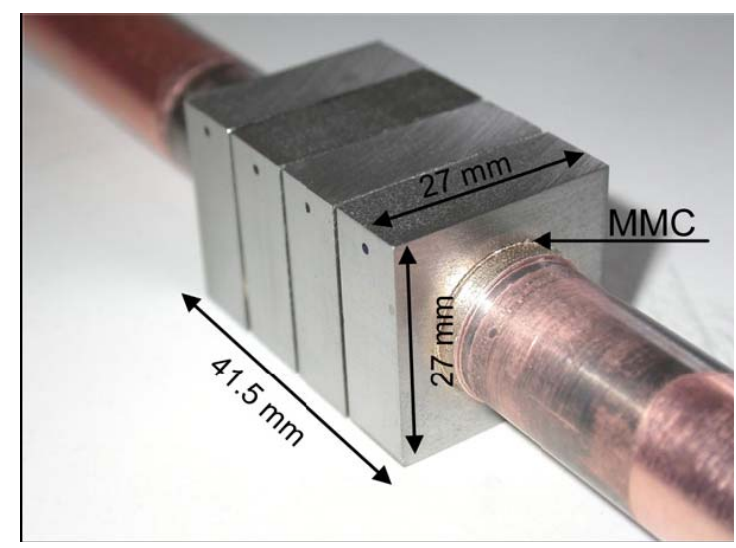

Fig. 1: Monoblock mock-up I after the synthesis processes

W fibre reinforcement is chosen to achieve an axial and tangential reinforcement.

The W blocks (Plansee SE) were obtained from bulk rolled material. The blocks were machined in order to obtain a grain orientation along the heat flux direction, which is perpendicular to the heated surface. The $\varnothing 17$ mm internal drillings of the $\mathrm{W}$ blocks were machined by wire-electro discharge and subsequently polished resulting in a low roughness of $\mathrm{Ra} \sim 0.2 \mu \mathrm{m}$. Holes $(\varnothing$ $1.1 \mathrm{~mm}$ ) were eroded up to $2.5 \mathrm{~mm}$ under the loaded surface of each $\mathrm{W}$ tile to install thermocouples for temperature measurements.

The following steps were performed to synthesize the monoblock mock-ups:

- The $100 \mu \mathrm{m}$ thin $\mathrm{W}$ fibre (OSRAM) was chemical etched for 10 minutes in a Murakami solution consisting of $100 \mathrm{ml} \mathrm{H}_{2} \mathrm{O}$ with $15 \mathrm{~g} \mathrm{NaOH}$ mixed in 1:1 ratio to $100 \mathrm{ml} \mathrm{H}_{2} \mathrm{O}$ with $15 \mathrm{~g}$ potassium ferricyanide $\mathrm{K}_{3}\left[\mathrm{Fe}(\mathrm{CN})_{6}\right]$.

- Subsequently, a thin 500 nm continuously graded W/Cu coating was deposited by physical vapour deposition (PVD) with a magnetron sputter device (Discovery 18DC/RF, Denton Vacuum Company) on the chemically etched $\mathrm{W}$ fibre. The $\mathrm{Cu}$ concentration is thereby increased in $\sim 2 \%$ steps from $\mathrm{W}$ to $\mathrm{Cu}$ by varying the power to the $\mathrm{Cu}$ and $\mathrm{W}$ electrodes. Before deposition, the fibres were etched by the argon plasma.

- $\quad$ The PVD coated fibres were electroplated with a 60 $\mu \mathrm{m} \mathrm{Cu}$ layer and then heat treated at $550^{\circ} \mathrm{C}$ for $1 \mathrm{~h}$ with a slow heating rate of $20^{\circ} \mathrm{C} / \mathrm{h}$. Thereafter, the fibres were annealed at $800^{\circ} \mathrm{C}$ for $1 \mathrm{~h}$.

- $\quad$ Subsequently, 100 fibres were $45^{\circ}$ aligned on a 20 $\mu \mathrm{m}$ thick $\mathrm{Cu}$ foil (99.9\%) cut in trapezium shape. In total four layers were implemented in such a way that two layers were orientated to $45^{\circ}$ and two layers to $-45^{\circ}$ in order to achieve a homogeneous $45^{\circ} \%$ $45 \% / 45 \%-45 \%$ reinforcement along the tube. The foils were wrapped around a $15 \mathrm{~mm}$ thick CuCr1Zr (0.5$1.2 \mathrm{wt} \% \mathrm{Cr}, 0.03-0.3 \mathrm{wt} \% \mathrm{Zr}$, rest $\mathrm{Cu}$ ) rod resulting in a gap-free $\pm 45^{\circ}$ orientated wrapped fibre reinforcement.
- The wrapped CuCr1Zr rod was encased by a $\mathrm{Cu}$ capsule, sealed by vacuum welding and consolidated by hot-isostatic pressing. The consolidated fibrereinforced compound was post machined to obtain a cylindrical clearance fit between the MMC reinforced CuCr1Zr rod and the W blocks. The 12 $\mathrm{mm}$ thick hole was drilled centrally through the $\mathrm{CuCr} 1 \mathrm{Zr}$ rod to functionalize it as a cooling tube.

- GEMCO alloy (Cu12Ge0.25Ni alloy from Wesgometals) has been used as brazing material for the joining of the cooling tube into $\mathrm{W}$. The four $\mathrm{W}$ blocks were beaded over the reinforced cooling tube plus brazing foil with a distance of $0.5 \mathrm{~mm}$ in between and heated at $\sim 970^{\circ} \mathrm{C}$ in a vacuum furnace. The properties of $\mathrm{CuCr} 1 \mathrm{Zr}$ were recovered by suitable brazing thermal cycle (solution treatment, fast cooling, aging: $480-550^{\circ} \mathrm{C}$ for $2-4$ hours).

\subsection{High heat flux tests}

High heat flux tests were carried out on two actively water-cooled monoblock mock-ups in the 1 MW neutral beam facility GLADIS at IPP Garching. The GLADIS facility was constructed for the testing of plasma-facing components (PFCs) under high heat fluxes similar to the expected loads in fusion devices [9]. The target water-cooling parameters of the facility are: maximal flow rate $8.5 \mathrm{l} / \mathrm{s}$, water inlet temperature $20{ }^{\circ} \mathrm{C}$ and a static pressure up to $1.6 \mathrm{MPa}$. More technical characteristics are described in detail in the literature [10, 11]. A hydrogen beam (20-30 keV) generates the heat load. A movable calorimeter was used to measure and to monitor the Gaussian beam profiles during the tests. The $\mathrm{Cu}$ bar, equipped with 17 calorimeter plugs can be vertically moved into the beam close to the installed target. The calorimeter returns to a position outside the vessel after the measurement.

Screening tests with increasing power density were applied to determine the ultimate loading conditions and pre-testing the performance of the mock-ups under heat load. The mock-ups were exposed to heat fluxes ranging from 0.2 to $6 \mathrm{MW} / \mathrm{m}^{2}$ for 30 seconds and for 20 seconds for 7, 8 and $10.5 \mathrm{MW} / \mathrm{m}^{2}$, respectively.

Additionally, the second mock-up was cyclically loaded with a heat flux of $10.5 \mathrm{MW} / \mathrm{m}^{2}$. To investigate the fatigue behaviour of the optimized monoblock mock-up, 25 cycles were performed. Every 60 seconds the mock-up was loaded for 20 seconds. The surface temperature of the exposed mock-ups was monitored by an infrared camera taking frames during each pulse and, additionally, by a one- and a two-colour pyrometer (temperature ranges: one-colour $650^{\circ} \mathrm{C}$ $2200^{\circ} \mathrm{C}$ and two-colour $700^{\circ} \mathrm{C}-1700^{\circ} \mathrm{C}$ ). A CCD video camera imaged the component during each pulse. The bulk temperatures of each $\mathrm{W}$ tile were measured by type-K thermocouples, which were placed $2.5 \mathrm{~mm}$ under the loaded surface. The applied cooling conditions (water velocity $12 \mathrm{~m} / \mathrm{s}$, inlet temperature 


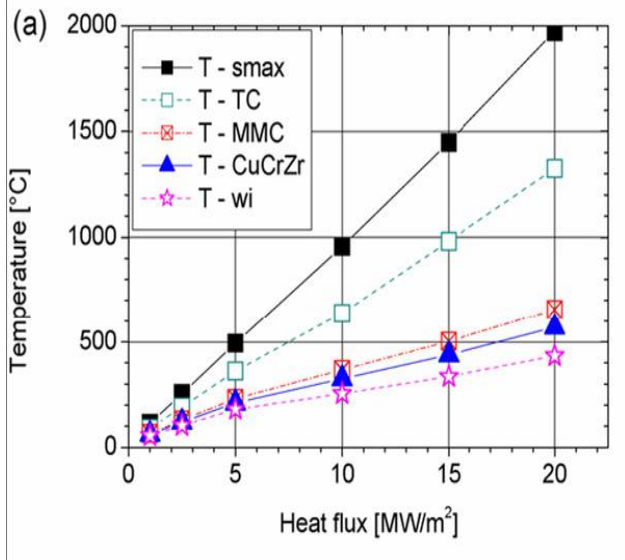

(b)

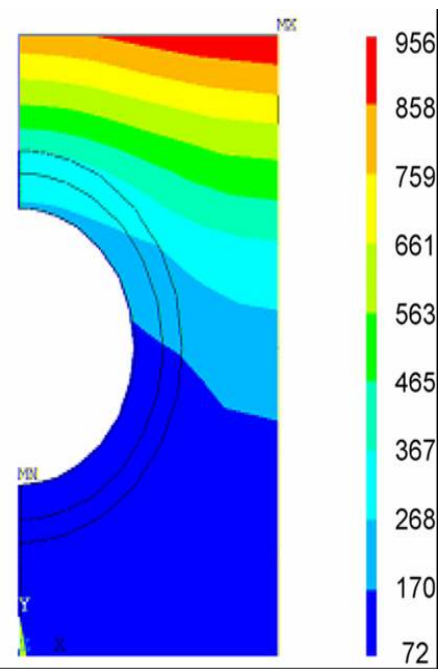

Fig. 2: a) Temperatures calculated by FEA of the W/Cu mock-up at the $\mathrm{W}$ surface (T-smax), at the thermocouple (T-TC), at the MMC (T-MMC), at the CuCr1Zr cooling tube (T-CuCrZr) and at the internal cooling tube wall (T-wi) in dependence of the heat flux. b) Temperature distribution plot of the half cross-section of the monoblock mock-up at a heat flux of $10 \mathrm{MW} / \mathrm{m}^{2}$. The figure shows the graphical representation of the temperature values of each element within the structure.

$15^{\circ} \mathrm{C}$ and static pressure $1 \mathrm{MPa}$ ) ensure the safe heat transfer in the regime of sub-cooled boiling up to $>20$ $\mathrm{MW} / \mathrm{m}^{2}$ power load and resulted in a maximum inner cooling tube temperature of $255^{\circ} \mathrm{C}$ for $10 \mathrm{MW} / \mathrm{m}^{2}$ and $335{ }^{\circ} \mathrm{C}$ for $15 \mathrm{MW} / \mathrm{m}^{2}$ loading, respectively. Despite the low cooling water temperature, this temperature range is comparable with the expected maximal inner tube temperature of $298{ }^{\circ} \mathrm{C}$ for the Model A reference design [3, Annex 4].

\subsection{Finite Element Modelling and Analysis}

A transient Finite Element Analysis (FEA) was performed to pre-estimate the thermal behaviour of a monoblock during HHF loading. The aim is to investigate the expected operation limits and to allow the interpretation of the HHF tests. The surface was exposed to 6 heat flux steps between 1 and $20 \mathrm{MW} / \mathrm{m}^{2}$ for 10 seconds, respectively. The monoblock cooling channel is supplied by pressurized cooling water according to the cooling parameters of the GLADIS facility. The ANSYS code was used for the FEA. The calculation of the heat transfer coefficient was implemented as independent routine. The heat transfer is calculated for the single phase regime up to the beginning of partial sub-cooled boiling. The routine implements the correlations for forced convection of the single phase regime, the calculation of onset of nucleate boiling, the sub-cooled boiling regime and the quadratic sum of convection and sub-cooled boiling during the partial sub-cooled boiling. A detailed description of the used equation is published in reference [12].

The expected temperature at the $\mathrm{W}$ tile surface ( $\mathrm{T}$ smax), at the thermocouples (T-TC), of the $\mathrm{W}_{\mathrm{f}} / \mathrm{Cu}$ MMC (T-MMC), of the CuCr1Zr cooling tube (T$\mathrm{CuCrZr}$ ) and at the internal tube wall (T-wi) were obtained by thermal FEA. After less than 10 seconds, all temperatures reach steady state. Figure 2a presents the calculated steady state temperature at dedicated heat fluxes between 1 and $20 \mathrm{MW} / \mathrm{m}^{2}$, which serves as basis for comparison with the experimental temperature data.

At heat fluxes higher than $15 \mathrm{MW} / \mathrm{m}^{2}$ the $\mathrm{CuCr} 1 \mathrm{Zr}$ cooling tube has to withstand temperatures higher than $440^{\circ} \mathrm{C}$. However, these temperatures are in the range of the operation temperature limit of the $\mathrm{CuCr} 1 \mathrm{Zr}$ material and would lead to loss of its precipitation hardening. Therefore, a thicker reinforcement or a complete replacement of the CuCr1Zr tube by the $\mathrm{W}_{\mathrm{f}} / \mathrm{Cu}$ MMC should be used for the future monoblock developments to increase the operational temperature.

Figure $2 \mathrm{~b}$ presents the temperature distribution of the half cross-section of the monoblock mock-up. The edges of the $\mathrm{W}$ blocks reach clearly the highest temperature of the loaded area since these are farthest away from the cooling channel.

\section{Discussion of high heat flux test results}

\subsection{Monoblock mock-up with optimized $W_{f} / C u M M C$}

Based on the optimization results from previous developments for the interface and the interlayer, a chemical etching procedure of the fibre and a continuously graded W/CuPVD interlayer followed by $800^{\circ} \mathrm{C}$ heat treatment were chosen to enhance the adhesion between fibre and matrix [13, 14]. The novel advanced $\mathrm{W}_{\mathrm{f}} / \mathrm{Cu}$ MMC was implemented into two monoblock mock-ups, I and II, reinforcing the interface between the plasma-facing material and the cooling channel (Fig. 1).

The next step was to demonstrate the use of the novel $\mathrm{W}_{\mathrm{f}} / \mathrm{Cu}$ MMC in a mock-up and to analyze and validate the performance of the component under high heat fluxes. 


\subsection{Temperature analysis of the heat-loaded mock-up}

Screening tests with increasing power density, starting from 0.2 to $10.5 \mathrm{MW} / \mathrm{m}^{2}$, were applied to determine the performances of the reinforced $\mathrm{W}$ CuCr1Zr interface. The results of mock-up I are presented in detail.

The temperature evolution with increasing heat load at the $\mathrm{W}$ tile surface and at the thermocouples of each tile is shown in Figure 3). The temperature data and the optical investigation by infrared and CCD camera of the first W block (\#1) and the last W block (\#4) show an overheating of these blocks starting already at low heat fluxes. Figure 4 presents the infrared images at heat flux pulses of $1,2,8$ and $10.5 \mathrm{MW} / \mathrm{m}^{2}$, respectively, identifying the hot spots on the mock-up I. It appears that these blocks were not correctly bonded to the MMC resulting in insufficient cooling.

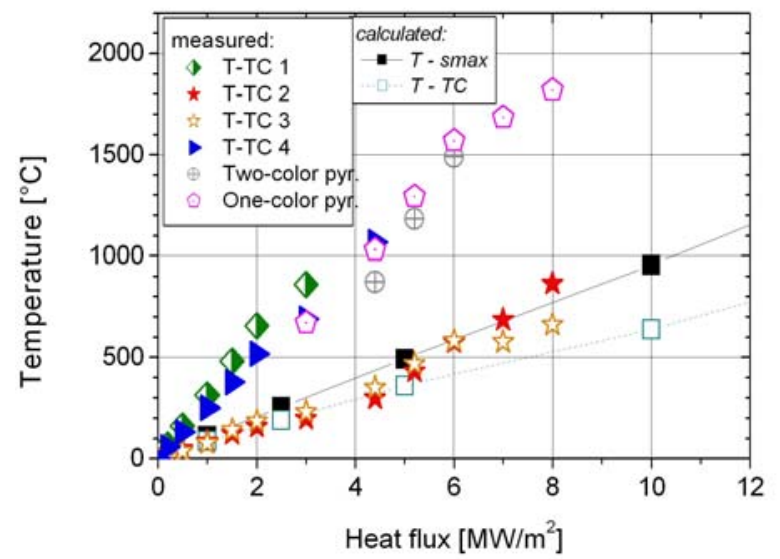

Fig. 3: Measured temperatures of installed thermocouples within the $\mathrm{W}$ blocks \#1 - \#4 of the $\mathrm{W}_{\mathrm{f}} / \mathrm{Cu}$ mock-up I (T-TC1 to 4 ) in dependence of different heat fluxes compared with the predicted surface (T-smax) and thermocouple temperature data by FEA (T-TC).

The two middle $\mathrm{W}$ blocks (\#2 and \#3) were correctly bonded and their temperature at different heat fluxes followed the temperature predicted by FEA. At higher heat fluxes, $7 \mathrm{MW} / \mathrm{m}^{2}$, the temperature of $\mathrm{W}$ block \#2 slightly differs from the temperature of block \#3 indicating some cooling problems. Possible explanation is the debonding at the $\mathrm{W}-\mathrm{CuCr} 1 \mathrm{Zr}$ interface or the influence of the overheated neighbour W block. Therefore, solely block \#3 was perfectly cooled until $10.5 \mathrm{MW} / \mathrm{m}^{2}$. Microscopic investigation of the cross-sections gave more information about the failure mechanism leading to a better understanding.

The thermocouples reached their limit $\left(1080^{\circ} \mathrm{C}\right)$ at the heat flux of $10.5 \mathrm{MW} / \mathrm{m}^{2}$, thus, no measurements were possible for higher heat fluxes. Therefore, the heat flux was not further increased. The surface temperatures determined by the two-colour pyrometer (spot size: $\varnothing=18 \mathrm{~mm}$ ) were measured on W block \#2, but follow and continue the temperature evolution of the thermocouple measurements of $\mathrm{W}$ block \#1 and \#4.

Therefore, it can be assumed that the measured temperature values correlated to the temperatures of the overheated and not-cooled W blocks. These data are not relevant for the accurately bonded blocks.

Regarding the temperature measurement methods, some concluding remarks should be taken into consideration: A sensitive parameter for one-colour pyrometer and infrared measurement is the emissivity factor $\varepsilon$, which strongly depends on the surface quality of the $\mathrm{W}$ blocks, the temperature and the detection wave length $\lambda$. Variations of the emissivity of \pm 0.02 correspond to temperature variations of $\pm 400^{\circ} \mathrm{C}$. Therefore, it is difficult to compare the exact values of the optically measured temperatures, i.e., the values of the one-colour pyrometer and infrared camera, with the calculated surface temperatures via FEA. A two-colour pyrometer was used as reference surface temperature measurement. Nevertheless, the most reliable temperature measurements during the HHF tests were achieved by the thermocouples. The IR camera was mainly used to identify growing delaminations between cooling tube and the $\mathrm{W}$ blocks.

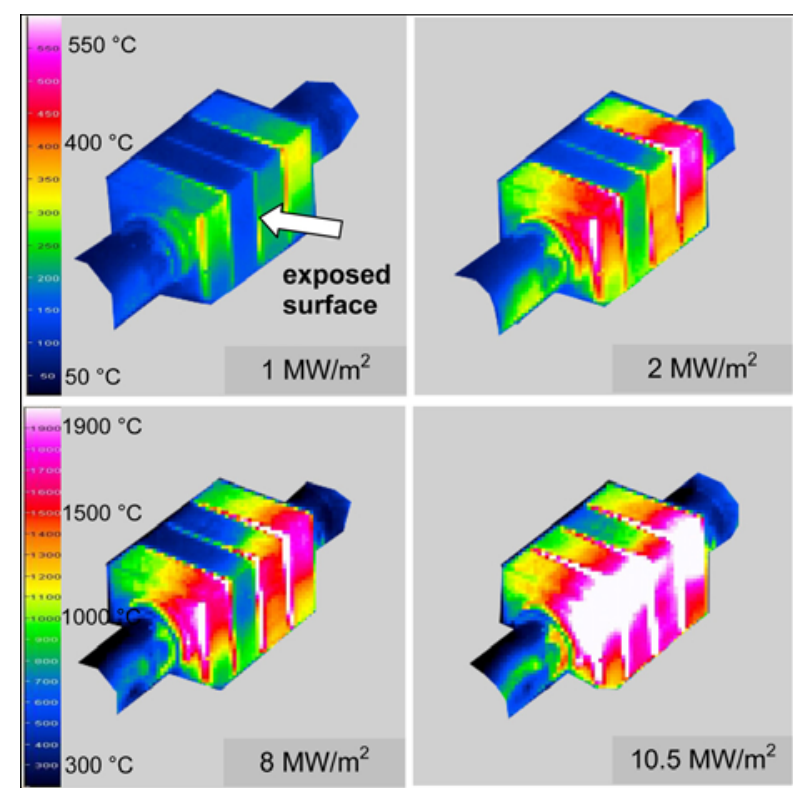

Fig. 4: Infrared camera images during heat load pulses at different power densities, identifying the hot spots on the mock-up I and indicating the highest temperatures at the edges of the $\mathrm{W}$ blocks. The images have been taken for = 0.15 . Note: The temperature range of the individual images is different to get a better visualisation (upper images: $25-600$ ${ }^{\circ} \mathrm{C}$, lower images: $200-2000{ }^{\circ} \mathrm{C}$ ).

\subsection{Cyclic test of optimized mock-up}

The mock-up II was tested under high heat fluxes analogue to the mock-up I. The same screening tests were performed. The results of the mock-up I could be confirmed. One W block showed an optimal stable 
thermal behaviour at heat fluxes of up to $10.5 \mathrm{MW} / \mathrm{m}^{2}$. Subsequently, the beam exposed surface was limited by a movable scraper to the surface of the stable $\mathrm{W}$ block. The pyrometers and infrared camera were positioned on this $\mathrm{W}$ block. The $\mathrm{W}$ block was cyclically loaded with a heat flux of $10.5 \mathrm{MW} / \mathrm{m}^{2}$. With each cycle the surface temperature increased slightly indicating a degradation of the $\mathrm{W}$ block cooling. After 25 cycles the variation of temperature was $\sim 400^{\circ} \mathrm{C}$. It can be assumed that during each cycle the bond between PFM and MMC degenerates further. This joint is the weak point of the component, which is supported by the post-mortem microscopic analysis.

\subsection{Microscopic investigations}

The $\mathrm{W}$ blocks \#1 and \#4 of mock-up I showed already gaps at the interface between PFM and MMC structure before heat flux testing, which indicates imperfections in the joining process. As the bonding technology between $\mathrm{W}$ and $\mathrm{CuCr} 1 \mathrm{Zr}$ is considered as well established technology, no failure was expected. The novelty in the processing was to incorporate the MMC within the W blocks instead of the pure CuCr1Zr tube. From technological point of view, all other materials are well known and no problems should arise, unless materials are contaminated with impurities which can create problems. Therefore, a possible explanation for the difference between the bonded $\mathrm{W}$ blocks \#2 and \#3 and the insufficiently bonded blocks \#1 and \#4 could be impurities at the brazing interface.

Optical microscopy and scanning electron microscopy (SEM) investigations were performed on metallographic cross-sections of the mock-up after the HHF tests. No micro-cracks were observed on the exposed surfaces of the $\mathrm{W}$ blocks. The microstructure of the beam-facing $\mathrm{W}$ half is dominated by coarse grains. The partly observed grain growth occurs due to the higher temperature. In contrast, the microstructure of the other $\mathrm{W}$ half is characterized by fine grains.

The cross-section analysis of each W block of the mock-up I was performed to check for delamination and debonding of the monoblock components. W block \#3 survived $10.5 \mathrm{MW} / \mathrm{m}^{2}$ without any visible damage of the compound. Figures $5 \mathrm{a}$ ) and b) present the crosssections of $\mathrm{W}$ block \#2 and \#4. The cross-section of \#4 indicates formation of large gaps between PFM, brazing foil and MMC, as it was already expected from the result of the temperature analysis during HHF tests. The cross-sections of $\mathrm{W}$ block \#2 and \#3 look similar. Both show mainly bonded zones between PFM and brazing foil.

The focus of the HHF tests was to investigate the performance of the $\mathrm{W}_{\mathrm{f}} / \mathrm{Cu}$ MMC implemented in the monoblock mock-up. The cross-section of the interface between $\mathrm{W}$ fibre and $\mathrm{Cu}$ matrix of the MMC in $\mathrm{W}$ block \#3 (SEM Figure 5c)) clearly shows that the fibre was well embedded like most of the fibres in the $\mathrm{Cu}$ matrix without any debonding. In the magnifications in Figures 5a) and b), no gap between MMC and
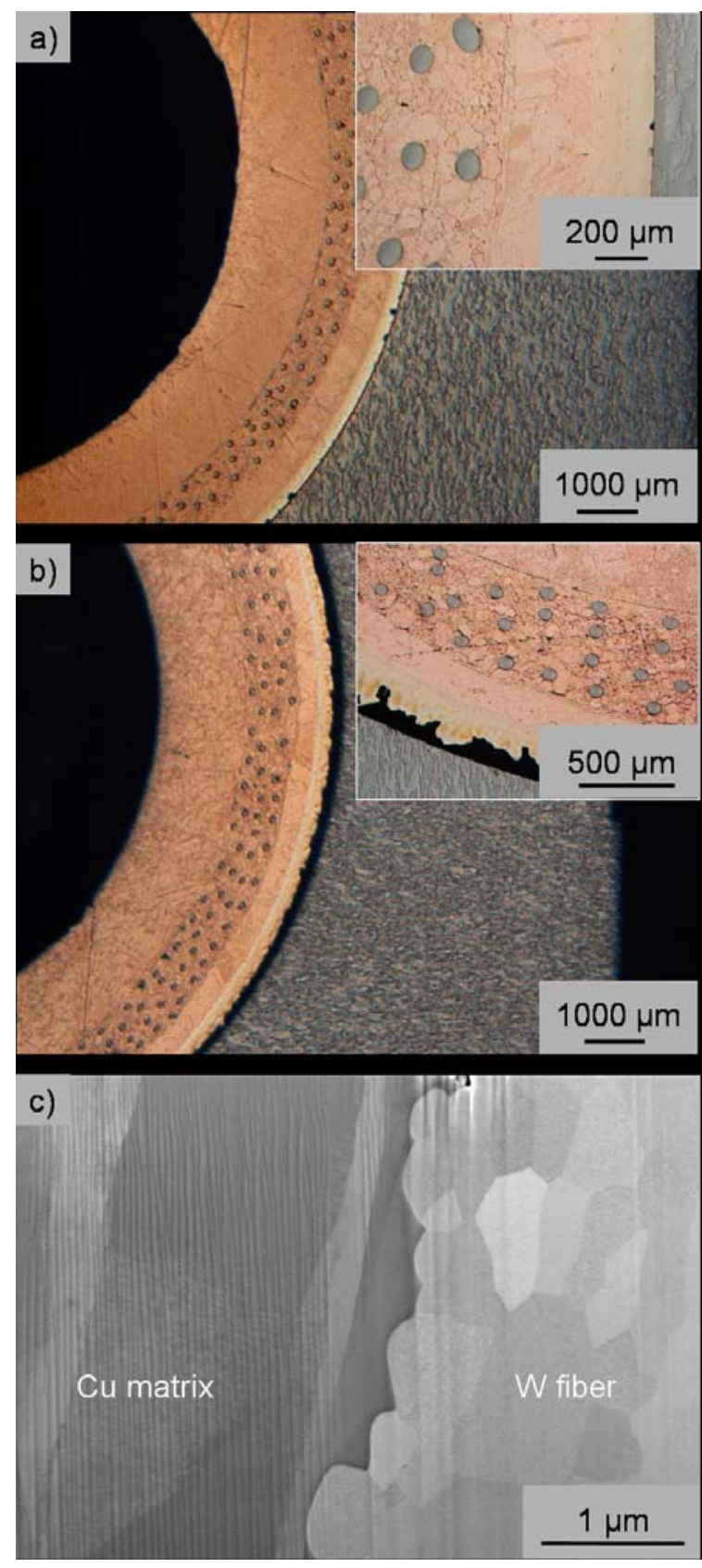

Fig. 5: Cross-section of W blocks of the mock-up I after heat flux test: a) W block \#2 indicates a good bonding between tube and PFM, b) cross-section of $\mathrm{W}$ block \#4 demonstrates the gap between tube and PFM, while c) cross-section of the interface between $\mathrm{W}$ fibre and $\mathrm{Cu}$ matrix of the MMC in $\mathrm{W}$ block \#3 confirms that the fibre stays well embedded (SEM image).

CuCr1Zr tube is visible. Thus, it can be concluded that the arrangement of the $\mathrm{W}$ fibres and the HIP process at the reinforced region leads to a complete consolidation. The synthesis method can be applied to implement $\mathrm{W}_{\mathrm{f}} / \mathrm{Cu}$ MMC as reinforcement or eventually as replacement of $\mathrm{CuCr} 1 \mathrm{Zr}$ material for the cooling tube. In this work four uni-directional layers were implemented solely due to the time consuming manual work. In principle, the number of fibre layers allows 
tailoring the fibre volume fraction and can be freely adjusted to obtain the required mechanical properties.

\section{Conclusions}

The novel advanced $\mathrm{W}_{\mathrm{f}} / \mathrm{Cu}$ MMC was implemented in monoblock mock-ups reinforcing the interface between the plasma-facing material and the cooling tube. As a proof of principle, its feasibility as an efficient heat sink material for water-cooled divertors in future fusion reactors was demonstrated in the high heat flux tests.

FEM simulations were performed to predict the temperature within the monoblock mock-up to understand the thermal behaviour of the component under high heat fluxes. The experimental temperature data and optical investigation of the first mock-up indicated that two of four W blocks were correctly bonded. Their thermal behaviour showed good agreement with the predicted temperatures during the heat flux experiments. At the highest heat flux of 10.5 $\mathrm{MW} / \mathrm{m}^{2}$ one of these $\mathrm{W}$ blocks remained bonded and showed a stable thermal behaviour.

The second monoblock mock-up confirmed the achieved results of the first monoblock mock-up, however unstable thermal behaviour appeared after 25 cycles at $10.5 \mathrm{MW} / \mathrm{m}^{2}$. It can be concluded that the weak point of the monoblock mock-up under heat flux tests was the conventional bonding technology between $\mathrm{W}$ and $\mathrm{W}_{\mathrm{f}} / \mathrm{Cu} \mathrm{MMC}$.

Furthermore, microscopic investigation showed that the implementation of the novel $\mathrm{W}_{\mathrm{f}} / \mathrm{Cu} \mathrm{MMC}$ was successful and the synthesis method can be applied to implement $\mathrm{W}_{\mathrm{f}} / \mathrm{Cu}$ MMC as reinforcement or eventually as replacement of CuCr1Zr material for the cooling tube. The fibres remained stably embedded in the matrix under high heat fluxes guaranteeing good performance of the whole component.

\section{Acknowledgement}

The authors would like thank OSRAM GmbH (Schwabmünchen) and Plansee SE (Reutte) for providing the $\mathrm{W}$ fibres and the $\mathrm{W}$ blocks, respectively.

A part of this work has been performed within the framework of the Integrated European Project „ExtreMat“ (contract NMP-CT-2004-500253) with financial support by the European Community. It only reflects the view of the authors and the European Community is not liable for any use of the information contained therein.

\section{References}

[1] Kukushkin, A.S., et al., Divertor issues on Iter and extrapolation to reactors. Fusion Engineering and Design, 2003. 65(3): p. 355-366.

[2] Maisonnier, D., Plant models for DEMO, in Burning
Plasma Diagnostics. 2008. p. 52-59.

[3] Maisonnier, D., et al., EFDA Final Report of the European Fusion Power Plant Conceptual Study (PPCS). 2004.

[4] ITER Materials Assessment Report. 2001, ITER Doc. G74 MA 1001-07011 W 0.2.

[5] You, J.H., Design feasibility study of a divertor component reinforced with fibrous metal matrix composite laminate. Journal of Nuclear Materials, 2005. 336(1): p. 97109.

[6] You, J.H. and H. Bolt, Structural analysis of a plasma facing component reinforced with fibrous metal matrix composite laminate. Journal of Nuclear Materials, 2004. 329333 (Part 1): p. 702-705.

[7] Bolt, H., et al., Plasma facing and high heat flux materials - needs for ITER and beyond, Journal of Nuclear Materials, 2002. 307: p. 43-52.

[8] Bolt, H., et al., Materials for the plasma-facing components of fusion reactors. Journal of Nuclear Materials, 2004. 329-333(Part 1): p. 66-73.

[9] You, J.-H. and I. Komarova, Probabilistic failure analysis of a water-cooled tungsten divertor: Impact of embrittlement. Journal of Nuclear Materials, 2008. 375(3): p. 283-289.

[10] Greuner, H., et al., High heat flux tests of the WENDELSTEIN 7-X pre-series target elements: Experimental evaluation of the thermo-mechanical behaviour. Fusion Engineering and Design, 2007. 82(15-24): p. 17131719.

[11] Greuner, H., et al., Design, performance and construction of a $2 \mathrm{MW}$ ion beam test facility for plasma facing components. Fusion Engineering and Design, 2005. 75-9: p. 345-350.

[12] Greuner, H., et al., Development of Divertor Targets for WENDELSTEIN 7-X, Fusion Technology Vol 1. 1998:p.263266.

[13] Herrmann, A., K. Schmid, M. Balden, H. Bolt. Interfacial optimization of tungsten fibre reinforced copper for high-temperature heat sink material for fusion application. Journal of Nuclear Materials, 2009. 386-388, 453- 456.

[14] Herrmann, A., Interface Optimization of Tungsten FiberReinforced Copper for Heat Sink Application, $\mathrm{PhD}$ thesis, TU München, 2009 